\title{
TRABALHO E EDUCAÇÃO NO CONTEXTO DO ENSINO SUPERIOR E A FORMAÇÃO DO ASSISTENTE SOCIAL
}

\author{
TRABAJO Y EDUCACIÓN EN EL CONTEXTO DE LA EDUCACIÓN SUPERIOR Y LA \\ FORMACIÓN DEL TRABAJADOR SOCIAL
}

\author{
WORK AND EDUCATION IN THE CONTEXT OF HIGHER EDUCATION AND THE \\ FORMATION OF SOCIAL WORKER
}

\author{
Maria Lúcia da SILVA ${ }^{1}$ \\ Raimunda Áurea Dias de SOUSA ${ }^{2}$
}

RESUMO: Este artigo apresenta uma discussão a respeito da importância da educação na análise do sentido do trabalho desenvolvido pelo profissional em Serviço Social quando atua na Política de Assistência Social na contemporaneidade. Assim, a pesquisa objetiva analisar a expansão do Ensino Superior, o caso do curso de Serviço Social, diante das transformações ocorridas na Política de Assistência Social e implicações no trabalho, que deixa de ser uso para alcançar cada vez mais a troca no mercado. Nessa perspectiva, é necessário compreender o processo de produção e reprodução do trabalho na expansão do capital e como os profissionais se percebem na própria dinâmica de desenvolvimento da práxis.

PALAVRAS-CHAVE: Educação. Ensino superior. Trabalho. Assistência social.

RESUMEN: Este artículo presenta una discusión sobre la educación en el análisis del sentido del trabajo desarrollado por el profesional en el Servicio Social cuando actúa en la Política de Asistencia Social. En este particular, la investigación tiene como objetivo el análisis de la expansión de la Educación Superior, en el caso del curso de Servicio Social, frente a los cambios en la política de Asistencia Social y sus implicaciones en el trabajo que ya no se usa para lograr cada vez más el cambio en el mercado. En esta perspectiva, es ineludible vislumbrar el proceso de producción y reproducción del trabajo en la expansión del capital y además como los profesionales perciben en la propia dinámica de desarrollo de la praxis.

PALABRAS CLAVE: Educación. Educación superior. Trabajo. Asistencia social.

ABSTRACT: This paper aims to present a discussion about the education in the analysis of the work developed by social service professionals when they act in the Social Assistance Policy. Therefore, this research intends to analyze the expansion of Higher Education, viz. the case of the Social Work study, in face of the changes that occur in Social Assistance Policy, and how

\footnotetext{
${ }^{1}$ Universidade de Pernambuco (UPE), Petrolina - PE - Brasil. Discente do Programa de Pós-Graduação Stricto Sensu - Formação de Professores e Práticas Interdisciplinares (PPGFPPI). Professora auxiliar na Faculdade de Ciências Aplicadas e Sociais de Petrolina - FACAPE. ORCID: <https://orcid.org/0000-0002-7307-0363>. E-mail: marsouza011@ hotmail.com

${ }^{2}$ Universidade de Pernambuco (UPE), Petrolina - PE - Brasil. Profa. Adjunta Colegiado de Geografia e PPGFPPI. ORCID: <https://orcid.org/0000-0002-4646-4500>.E-mail: aurea.souza@upe.br
} 
their implication on the job that is no longer used to achieve an increasingly change in the market. In this perspective, it is essential to realize the process of production and reproduction of the work of expansion of the capital, as well as how the professionals perceive their developmental dynamics of the Praxis.

Keywords: Education. Higher education. Work. Welfare.

\section{Introdução}

As transformações que vêm ocorrendo no mundo do trabalho, desde a precarização ao desemprego advindos da própria lógica neoliberal, instigou a necessidade de pensar sobre as condições de trabalho dos assistentes sociais, que sofrem os efeitos deletérios da dinâmica de financeirização do capital em sua expansão, provocando não somente a ausência do trabalho protegido para os trabalhadores da assistência social;, como também a descontinuidade dos serviços ofertados para aqueles trabalhadores "sobrantes" da tensa relação entre capital e trabalho.

Nesse contexto, a pesquisa ocorre com profissionais da Política de Assistência social, bem como estudantes do curso de Serviço Social, cuja problemática centra-se: como a educação, mais precisamente, o curso de Serviço Social, tem percebido as transformações ocorridas na política de Assistência Social que, por sua vez, repercute no trabalho como condição de realização, ou seja, de valor de uso da categoria?

Para desvendar a problemática, traçou-se como objetivo analisar a relação entre trabalho e educação no contexto do curso de Serviço Social, diante das transformações ocorridas na Política de Assistência Social e implicações na formação do assistente social que deixa de ser da realização para alcançar cada vez mais a troca no mercado.

A pesquisa tem caráter qualitativo/quantitativa; de acordo Minayo (1994, p. 22), os "dados não se opõem, pelo contrário se complementam, pois, a realidade abrangida por eles interage e se complementa". A mesma teve início com o processo denominado fase exploratória, permitindo interrogar/questionar os pressupostos, as teorias que versam sobre o campo de estudo, bem como as questões que levariam aos desdobramentos para o trabalho de campo.

Para a viabilização da investigação, utilizou-se dos seguintes procedimentos ${ }^{3}$ :

${ }^{3}$ A pesquisa está amparada pelos dispositivos legais do Comitê de Ética sob o Parecer de n ${ }^{\circ}: 2.504 .128$ e CAAE: 80056017.6.0000.5207. 
a) Levantamento e análise bibliográfica: ocorreu durante todo o período de realização da pesquisa o levantamento, a leitura e a análise da bibliografia disponível, no sentido de buscar consistência teórica aos seus referentes básicos: Trabalho, Política de Assistência Social e Educação.

b) Análise documental: foram analisadas as legislações vigentes criadas no âmbito da Seguridade Social, as quais fundamentam a Assistência Social enquanto política de Estado, tais como: Constituição Federal (1988), Lei Orgânica da Assistência Social (1993), Política Nacional de Assistência Social (2004), Sistema Único de Assistência Social (SUAS), Norma Operacional Básica (NOB-RH).

c) Trabalho de campo: foram aplicados questionários a 20 profissionais da política de assistência social; para os estudantes, ocorreram em dois momentos: no primeiro dia de aula, no mês de agosto/17, a 15 estudantes da disciplina oficina de Assistência Social do VIII período da instituição de ensino FACAPE, e no segundo momento participaram 10 estudantes no final da disciplina, em dezembro/17.

A coleta de dados estatísticos está sendo uma etapa de extrema importância na consecução da pesquisa. Para tal, estabeleceu-se um recorte temporal a partir dos anos 2000, por entender que nesse momento passa a ser perceptíveis os efeitos da Política de Assistência Social e a expansão do Ensino Superior, particularmente, o curso de Serviço Social

\section{A Política de Assistência Social e a expansão do ensino superior a distância - O caso de Serviço Social}

Na contemporaneidade, apesar dos avanços constituídos e legitimados pelas legislações vigentes, as políticas sociais são pensadas com foco no indivíduo e o seu pleno desenvolvimento, não alterando o quadro anacrônico da meritocracia adotada na organização das práticas assistenciais.

Evidencia-se a facilidade de o sistema capitalista precarizar os trabalhadores que estão no exercício profissional, bem como aqueles que são assistidos pela política social, uma vez que estas são criadas e desfeitas com facilidade, reiterando a desigualdade social e o aprofundamento das refrações da questão social.

No governo Lula (2003 - 2011), é importante considerar a implementação e aprovação da Política Nacional de Assistência Social (PNAS/2004) enquanto política pública de Estado, sendo esta desdobramento do que já estava instituído pela Constituição Federal de 1988 e a Lei Orgânica da Assistência Social (LOAS) nº 8.742 de 1993, como um pilar do Sistema de 
Proteção Social. Posteriormente, tem-se a criação da Lei no 12.435/2011 que a regulamenta enquanto Sistema Único de Assistência Social (SUAS).

Mota (2012, p. 35) delineia que: "na primeira etapa do seu mandato, foram realizadas as contrarreformas da previdência e educação, concomitantes ao aumento das taxas de juros, enquanto no mesmo período expandia-se a assistência social". Tais argumentos apresentados pela autora justificam a ampliação dos programas sociais e a contratação de assistentes sociais, sem as devidas condições de trabalho, ampliando a instabilidade nas relações de trabalho.

É sob este viés de expansão das políticas sociais, em especial a assistência social, que o curso de Serviço Social é implantado na instituição de ensino superior - Faculdade de Ciências Aplicadas e Sociais de Petrolina (FACAPE) no ano de 2013, que abrange a Região Administrativa Integrada de Desenvolvimento (RIDE). Tendo a sua primeira turma no segundo semestre desse mesmo ano, dispondo de um Projeto Pedagógico que, embora não compreendesse as especificidades de totalidade da formação em Serviço Social, sendo necessária a reestruturação pelo Núcleo Docente Estruturante (NDE); no entanto, já apontava a importância de uma formação presencial no Polo Petrolina/Juazeiro.

É importante considerar que, tendo em vista a Assistência Social ser tratada enquanto política de Estado, foi constituído o Ministério de Desenvolvimento Social e Combate à Fome no ano de 2004. Paralelas a esse contexto de mudanças no bojo da assistência social com a criação de uma rede de serviços, expandiam-se as formações em Serviço Social à distância; concomitantemente se ampliou sobremaneira o quantitativo de profissionais admitidos nas condições de trabalho adversas. As autoras Amaral e Mota (2014) dialogam sobre esse processo de expansão:

No caso do Serviço Social, destaca-se a avassaladora expansão do ensino privado e na modalidade à distância, que forma uma nova geração de assistentes sociais que se afasta, cada vez mais, das diretrizes curriculares da profissão, determinando o surgimento de um verdadeiro "exército de reserva profissional". Esse excedente profissional interfere sobremaneira no mercado de trabalho e na quase generalizada precarização do trabalho dos assistentes sociais. (p. 36-37)

Tais mecanismos, adotados na era Lula, propiciaram um mercado educacional que compreendesse a própria dinâmica da economia, de forma aligeirada, módico, garantindo expressivo número de trabalhadores, para a inserção nos programas sociais da Assistência Social. Guerra (2014) sinaliza que:

A centralidade na política de assistência social e a extensão da sua lógica a outras políticas resultam na expansão do mercado de trabalho profissional e 
vêm na mesma direção da expansão dos cursos à distância que acabam atendendo boa parte daqueles que se interessam por inserir-se neste "novo", porém precarizado, mercado de trabalho profissional. A expansão dos serviços assistenciais. (p. 53)

A necessidade de "aliviar a pobreza" passou a exigir a criação de políticas compensatórias para inserção dos pobres na sociedade, mesmo que via consumo de bens materiais. Diante da expansão da política, o profissional em Serviço Social passou a ser perceptível pelas empresas ligadas ao setor da educação privada, com o intuito de adquirir uma formação rápida para ocupar esses postos de trabalho.

Seguindo essa linha de pensamento, Iamamoto (2014a) aponta:

Certamente o espírito empreendedor do empresariado da educação leva-o a investir onde existe a demanda: a regulamentação e municipalização da assistência social, aliada à saúde, vêm ampliando a oferta de trabalho nos municípios, o que certamente tem interferências no jogo político local, frequentemente marcados por características e traços populistas clientelistas e coronelistas herdados da história política de base municipalista no país. (p. 443)

Desta forma, não é diferente o que acontece no Polo Petrolina/Juazeiro, com a proliferação dos cursos a distância, conforme aponta a Figura - 01, quando identifica o quantitativo de instituições de Educação a Distância. É importante considerar a existência da concorrência entre o curso presencial na instituição FACAPE e demais instituições abaixo relacionadas.

Lembrando que, apesar do curso ofertado na FACAPE estar dentro do viés de modalidade presencial, não o exime da lógica privada de ensino, quando os seus alunos realizam pagamentos mensais para obtenção da formação em Serviço Social, durante o período de quatro anos.

Figura 01 - Universidades presentes no polo Petrolina/Juazeiro com curso em Serviço Social na modalidade a distância

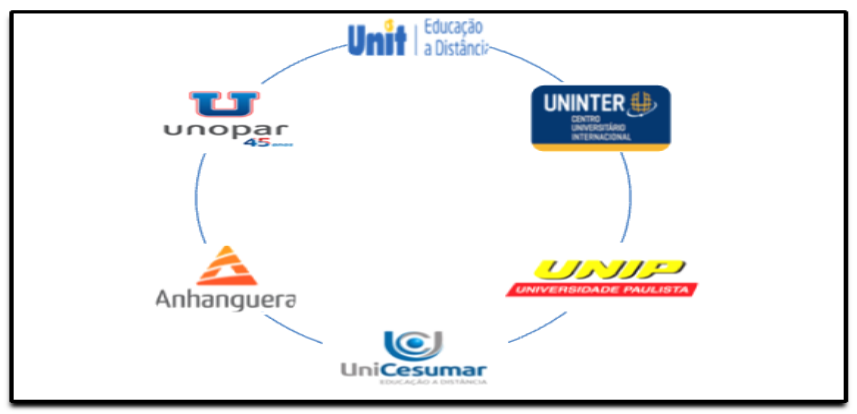

Fonte: Elaboração própria 
A proliferação das universidades demonstra o empreendimento na educação de forma lucrativa, dentro de uma perspectiva mercadológica da educação, direcionada pelos condicionantes neoliberais. Sobre tais fatos, Iamamoto (2014a) revela:

O propósito foi o de compatibilizar o ensino superior com os ditames de financeirização da economia, fazendo com que as descobertas científicas e o seu emprego na produção se tornem meios de obtenção de lucros excedentes, o que justifica a orientação de submeter a universidade aos interesses empresariais. (p. 433)

O panorama no campo do ensino universitário em Serviço Social demonstra os reais interesses de um grupo hegemônico que domina o mercado em ensino a distância, conhecido como grupo Kroton ${ }^{4}$. A empresa tem foro no município de Belo Horizonte/MG, com ações e investimentos na bolsa de valores em Nova York ${ }^{5}$, e está alicerçada sob o discurso "paixão por educar".

Ainda sobre o grupo Kroton, por meio de pesquisa realizada no site da empresa, verificou-se o raio de atuação em todos os estados brasileiros, com polos de Educação a Distância (EAD) sendo liderados pelas marcas: Anhanguera e Unopar, apresentando elo entre as demais instituições de ensino a distância, as quais são representadas por meio de outros empreendimentos e/ou marcas na distribuição dos referidos polos.

O quadro de inflexões que no país vem sendo colocado desde os anos 2000, quando da intensificação do processo de privatização do ensino superior e financiamento pelo Banco Nacional de Desenvolvimento Social (BNDES), ocorre paralelo às políticas sociais, as quais são realizadas de forma casuísticas e atendem aos interesses do grande capital, por meio das exigências racionalizantes dos bancos multilaterais.

${ }^{4}$ Entre 2003 e 2016, o Ensino a Distância cresceu a uma taxa composta de 30\%, sendo a modalidade que mais cresceu do Ensino Superior. Entre 2015 e 2016, o EAD registrou alta de 7\%, contando com 1,5 milhões de alunos matriculados em 2016, segundo dados do INEP/MEC. Abaixo demonstramos a evolução no número de matrículas no ensino superior à distância, segregado entre matrículas em instituições públicas e matrículas em instituições privadas. Atualmente conta com 1.210 polos credenciados pelo MEC, presente em 877 municípios. Pesquisado em: 04 jun. 2018. Disponível em: <http://ri.kroton.com.br/pt-br/a-kroton/mercados-de-atuacao/>.

${ }^{5}$ A Kroton negocia suas ações ordinárias no segmento Novo Mercado da B3 sob o símbolo "KROT3" e no mercado de balcão (OTCQX) em Nova Iorque sob o símbolo "KROTY”. As ações ordinárias da Kroton conferem aos seus titulares os direitos e vantagens inerentes às ações ordinárias de sua emissão e a elas subjacentes, assegurando ao seu titular o direito de participar das suas Assembleias Gerais e nelas exercer todas as prerrogativas conferidas às ações ordinárias. Adicionalmente, os titulares das ações ordinárias da Companhia fazem jus a todos os benefícios assegurados às suas ações ordinárias de emissão, inclusive ao recebimento integral de dividendos e demais proventos de qualquer natureza que vierem a ser declarados a partir da data de sua subscrição/aquisição, nos termos do previsto na Lei das Sociedades por Ações, no Regulamento de Listagem do Novo Mercado e no Estatuto Social da Kroton. Pesquisado em: 04 jun. 2018. Disponível em: <http://ri.kroton.com.br/pt-br/a-kroton/mercados-deatuacao/>. 
Para tanto, Guerra (2014, p. 54) aponta que o modelo de Estado idealizado requer um perfil de profissional para atuar sob as seguintes situações:

[...] as requisições sócio profissionais e políticas colocadas as assistentes sociais, são para atuarem em diversos programas de controle social, dentre eles de remoções compulsórias (desalojamento), internação compulsória, depoimento sem dano, utilizando várias formas de intimidação e pressão, e dos Programas de Aceleração do Crescimento - PAC, do que decorre um conjunto de demandas de regras previstas nos manuais de operacionalização com as exigências dos bancos multilaterais.

Todo esse aparato desenvolvido pela dinâmica do capital exige por meio dessa formação um perfil profissional que atenda ao processo de políticas para pobres, o que permite o retorno de práticas assistencialistas, na forma de ações pontuais e imediatistas. Sobre essa tendência de racionalização nas políticas sociais, atende a premissa do mercado quando:

O capital é portador da racionalidade sociopolítica e o agente principal do bem-estar da República. Ela tende a deslocar direitos sociais, entre os quais a educação superior, para o setor de prestação de serviços definido pelo mercado, segundo os critérios de produtividade, competição e eficiência, desfigurando-a e mutilando-a, ao tempo em que comprime o espaço público e amplia o espaço privado. (IAMAMOTO, 2014a, p. 438)

Além dessas características traçadas pelo aligeiramento, é atribuído ao aluno o mérito da formação, quando este percorre outros caminhos para a compreensão da prática profissional, tendo em vista a lacuna proporcionada pela própria formação, na deficiência do tripé: ensino, pesquisa e extensão, como também ausência de acompanhamento sistemático em estágio curricular.

É necessário elucidar que a mundialização do capital tem ampla repercussão nas políticas sociais, em especial na Assistência Social, quando este/a trabalhador/a se insere no mercado de trabalho de forma precarizada, contratos temporários, que levam a uma descontinuidade e fragmentação do atendimento à população vulnerabilizada. As estratégias favorecem as diretrizes de "focalização, descentralização, desfinanciamento e regressão do legado dos direitos do trabalho assalariado" (IAMAMOTO, 2014a, p. 433).

Nessa direção sobre o ensino a distância, que vem sendo massificado de forma escalar, o gráfico 02 demonstra o quantitativo de profissionais na modalidade de ensino presencial e a distância em Serviço Social no Polo Petrolina/Juazeiro das referidas secretarias municipais de Assistência Social. 
Gráfico 01 - Profissionais com formação em ensino a distância e presencial na Política de Assistência Social do polo Petrolina/Juazeiro

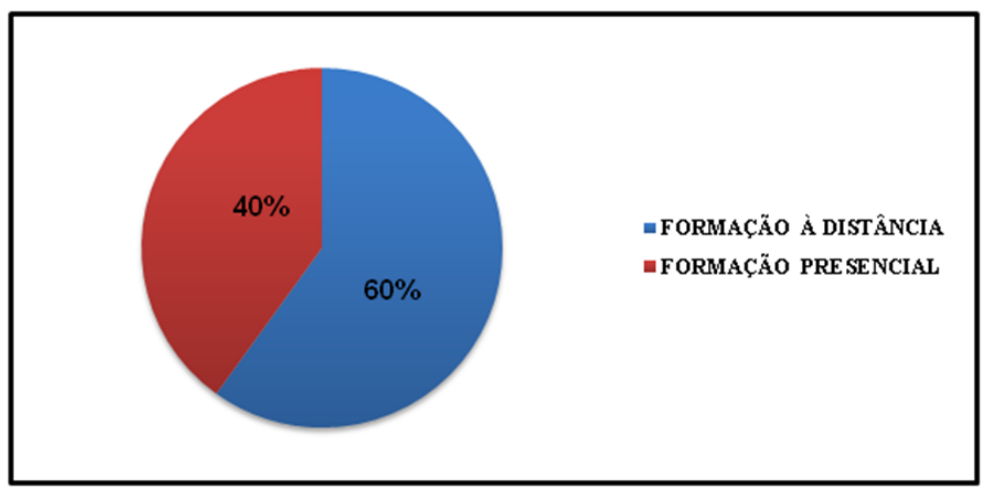

Fonte: Elaboração própria com base em pesquisa de campo (2018)

A questão central do estudo não é apontar exclusivamente a modalidade de ensino a distância. Entretanto, o que se quer apresentar é que o modelo de ensino difundido cotidianamente fortalece novos nichos de mercado e atende tão somente aos interesses de grupos hegemônicos, que discutem os rumos da educação, numa congruência empresarial, de estímulos a uma formação desassociada do tripé: ensino, pesquisa e extensão, redirecionando os caminhos das universidades no Brasil.

A formação aligeirada vai de encontro ao Projeto Político do Serviço Social. As alterações realizadas nas Diretrizes Curriculares (1996) apontam novo sentido curricular e permitem viabilizar uma formação nas dimensões: teórico-metodológica, ético-política e técnico-operativa, tendo como premissa a apreensão crítica dos processos sociais com perspectiva de totalidade.

O debate sobre a assistência social e educação é preponderante mediante a compreensão da dinâmica de expansão do capital, a qual altera a modalidade de ensino, sob o espectro de ampliar suas taxas de acumulação, para garantir maior lucratividade no campo da educação de forma escalar, tendo como exemplo o quantitativo de universidades nos municípios polo da pesquisa.

\section{O trabalho do/a Assistente Social no Polo Petrolina-PE/Juazeiro-BA}

O Estado na sua contradição reconhece a questão social e intervém por meio de um conjunto de políticas sociais, como forma de controlar a classe trabalhadora e subordiná-la ao jogo de forças e intensificação por meio dos seus aparatos de exploração da única fonte de produção de riqueza social, que é o trabalho. 
No entanto, é necessário especificar que o assistente social lida com as diferentes manifestações da questão social, sendo essa "forte desigualdade, desemprego, fome, doenças, penúria, desamparo ante conjuntura econômica adversa” (NETTO, 2011b, p. 155).

O assistente social atua nas expressões da questão social, provocada pela não socialização da riqueza, que é engendrada pela/o coletivo de trabalhadores/as. Nesse confronto entre Estado, trabalho e capital, configura-se a inserção do assistente social nos diferentes espaços ocupacionais, seja nas áreas: da família, habitação, saúde, educação, sistema prisional, assistência social, seja em outras.

É no cotidiano que se realiza o fazer profissional do assistente social, exercendo as suas atribuições privativas, de acordo com a Lei de Regulamentação da Profissão no 8.662/93, Art. $5^{\circ}$, do inciso I ao XII. O inciso primeiro delineia sobre as atividades que estão circunscritas no âmbito de "coordenar, elaborar, executar, supervisionar e avaliar estudos, pesquisas, planos, programas e projetos na área de Serviço Social” (p. 46).

Nesse contexto, o profissional é desafiado a decifrar as dimensões que circundam as demandas do universal ao particular; impulsionado pela consolidação de um projeto societário aliado ao projeto profissional, permeados por princípios fundamentais, debruçados em uma sociedade justa e igualitária. A autora Iamamoto (2014a, p. 222) concebe que:

Pensar o projeto profissional supõe articular uma dupla dimensão: de um lado, as condições macrosocietárias, que estabelecem o terreno sócio-histórico em que se exerce a profissão, seus limites e possibilidades; e de outro, as respostas sócio-históricas, ético-políticas e técnicas de agentes profissionais a esse contexto, as quais traduzem como esses limites e possibilidades são analisados, apropriados e projetados pelos assistentes sociais.

Projetos societários são indissociáveis dos projetos profissionais, sendo que tal processo poderá ser construído a partir de uma formação acadêmica que contemple e explicite a dinâmica histórica, econômica, sociológica e cultural da sociedade. É por meio desse constructo de ampla defesa pela participação social que se estabelece a base do Serviço Social, rompendo com os muros endógenos e conservadores que permearam o campo da prática na assistência social sob o invólucro da benemerência.

Analisar o campo de atuação dos assistentes sociais na Assistência Social do Polo Petrolina/Juazeiro incumbe à compreensão das dimensões que perfaz o exercício profissional, contribuindo para o desvelamento do verdadeiro sentido do trabalho, seja no âmbito público ou no âmbito privado, nos quais a política é desenvolvida. 
As alterações desencadeadas nos espaços de trabalho do assistente social são provocadas pela crescente financeirização do capital, que exige não somente a flexibilização das legislações trabalhistas, bem como daquelas que são criadas para legitimar as políticas sociais.

Sobre a necessidade de controle das legislações trabalhistas, Antunes (2015, p. 130) assegura:

É nesse quadro, caracterizado por um processo de precarização estrutural do trabalho, os capitais globais estão exigindo também o desmonte da legislação social protetora do trabalho. E flexibilizar a legislação social do trabalho significa, não é possível ter nenhuma ilusão sobre isso, aumentar ainda mais os mecanismos de extração dos sobretrabalho, ampliar as formas de precarização e destruição dos direitos sociais arduamente conquistados pela classe trabalhadora.

Assim como Antunes, Conceição (2005, p. 166) reforça o papel do Estado, sinalizando que o "Estado deixa de ser o agente direto do crescimento, e passa a ser o elemento catalisador e impulsionador da sociedade civil e da empresa privada no combate à pobreza".

O discurso estatal brasileiro está alicerçado pelos pilares internacionais do Banco Mundial. De acordo com o Relatório Mundial (2017, p. 2), a missão desse grupo é "erradicar a pobreza extrema até 2030 mediante a redução da percentagem de pessoas que vivem com menos de US\$ 1,90 por dia; em tempo, impulsionar a prosperidade compartilhada mediante a promoção do aumento da renda dos $40 \%$ mais pobres em cada país".

O passivo histórico de desigualdades no Brasil vem ocorrendo de forma espacializada e desigual, as mudanças ocorridas são tímidas, o que ocasiona acentuadamente as mazelas sociais, provocadas pela concentração de renda, engendrada na relação capital e trabalho, ampliando as inúmeras expressões da questão social, bem como o quantitativo de trabalhadores/as dependentes das políticas sociais.

O discurso criado pelo próprio Estado é contraditório e caminha na contramão da emancipação do indivíduo, tornando-o dependente das políticas compensatórias, as quais são criadas para manutenção do exército de trabalhadores, ampliando de forma escalar a pobreza. Nesse sentido, os autores Santo, Jimenez e Gonçalves (2017, p. 72), relatam que "o Estado não pode admitir sua incoerência, age pela via da política, da assistência, das medidas compensatórias e principalmente pela via da educação, uma importante e eficiente estratégia de disseminação da lógica burguesa".

As transformações ocorridas no mundo do trabalho em nome da eficácia e da qualidade total reduzem drasticamente os gastos sociais públicos. $\mathrm{O}$ discurso de combate à pobreza tem sido utilizado em diversos formatos e espaços, compondo slogans de campanhas eleitorais. Os 
dados apresentados pelos principais centros de pesquisas têm dado visibilidade às desigualdades sociais, porém tem ocorrido de forma midiática e utilizado dentro de uma concepção de política pública restritiva, o que amplia e reforça o contingente de trabalhadores em situação de miséria.

Nesse percurso, o assistente social sofre os deletérios desenfreados de extração do trabalho, sob o espectro da flexibilização, comprometendo as condições de trabalho. O Estado, no seu papel de regulador da economia, altera as legislações sociais, em tempo, garante a reprodução do capital, provocando a desestruturação social.

E nesse quadro, caracterizado por um processo de precarização estrutural do trabalho, os capitais globais estão exigindo também o desmonte da legislação social protetora do trabalho. E flexibilizar a legislação social do trabalho significa - não é possível ter nenhuma ilusão sobre isso - aumentar ainda mais os mecanismos de extração sobretrabalho, ampliar as formas de precarização e destruição dos direitos sociais arduamente conquistados pela classe trabalhadora, desde o início da Revolução Industrial, na Inglaterra, e especialmente pós 1930, quando se toma o exemplo brasileiro. (ANTUNES, 2015, p. 130)

A dicotomia vivenciada pelos assistentes sociais na sua prática profissional é constante não apenas pela sua vinculação às instituições públicas e/ou não governamentais, mediante a precarização nas relações de trabalho, como também pela ausência de investimentos com o social, que aflige diretamente os trabalhadores que não estão inseridos nos espaços de trabalho, mediante a contradição originada pela expansão do capital.

\section{Considerações finais}

A dinâmica do processo expansionista do capital propõe não somente a redução da intervenção estatal na economia, mas também a necessidade de controlar os trabalhadores, em tempo, acionar o exército de reserva, quando houver interesse por parte daqueles que dominam o próprio mercado de trabalho.

O aparato institucional criado pelo próprio Estado, por meio das políticas sociais, com caráter de racionalização, é desenvolvido de forma precária, descontínua e flexível, com implicações na vida dos trabalhadores, tanto daqueles que vendem sua força produtiva, como daqueles que são atendidos pelas políticas sociais de caráter compensatório. Os desdobramentos de tais práticas ocorrem na assistência social de forma escalar, coadunando com o Polo Petrolina/Juazeiro. 
Não obstante todos os retrocessos desencadeados com a imposição de uma cultura de dominação, permeados pela lógica destrutiva do capital, no qual tem acrescido veementemente a política de assistência social, ofertada aquela população "sobrante" de forma focalista, fragmentada e descentralizada. Ao mesmo tempo, tem se ampliando os estudos e pesquisas pelos profissionais do Serviço Social com base na teoria crítica, contra os desmontes da Seguridade Social. É tempo de resistir às intempéries que advêm, é necessário estar fortalecido, e o caminho a seguir é a busca constante pelo conhecimento, o qual permite continuar na caminhada.

Desta forma, a pesquisa em andamento, sensibiliza para análise da relação entre educação, trabalho e a Política de Assistência Social como indissociável ao entendimento da acumulação flexível do capital na Política de Assistência em duas frentes: primeiro, na extração da mais-valia adquirida nas contratações temporárias, que impedem a continuidade das políticas de governo; segundo, nos usuários, que não conseguem ser atendidos (beneficiados) pela referida política, gerando, assim, mais pobreza.

Mostra ainda, que a expansão dos cursos de Serviço Social, no Brasil e em especial em Petrolina/Juazeiro, está ligada à criação de políticas de assistência social para diminuir na análise do Estado o número de excluídos da condição mínima da reprodução humana - direito à saúde e alimentação.

\section{REFERÊNCIAS}

ANTUNES, Ricardo. Adeus ao Trabalho?: ensaio sobre as metamorfoses e a centralidade do mundo do trabalho. São Paulo: Cortez, 2015.

ASSOCIAÇÃO BRASILEIRA DE ENSINO E PESQUISA EM SERVIÇO SOCIAL (ABEPSS), Diretrizes Gerais para o curso de Serviço Social, Rio de Janeiro, 1996

BANCO MUNDIAL. Relatório Anual de 2017 do Banco Mundial, Washington, DC: Banco Mundial. doi: 10.1596/978-1-4648-1126-5. Licença: Creative Commons Attribution — Non Commercial — No Derivatives 3.0 IGO (CC BY-NC-ND 3.0 IGO). 2017.

BRASIL. Decreto lei n 593, de 27 de maio de 1969, Autoriza o Poder Executivo a instituir uma fundação destinada a prestar assistência à maternidade, à infância e a adolescência.

BRASIL. Lei no 8.742. Lei Orgânica da Assistência Social (LOAS). Brasília, DF: 7 de dezembro de 1993.

BRASIL. Lei complementar $\mathbf{n}^{\mathbf{0}} \mathbf{1 1 3}$, de 19 de Setembro de 2001. Autoriza o Poder Executivo a criar a Região Administrativa Integrada de Desenvolvimento do Polo Petrolina/PE e 
Juazeiro/BA e instituir o Programa Especial de Desenvolvimento do Polo Petrolina/PE e Juazeiro/BA.

BRASIL. Política Nacional de Assistência Social. Brasília, 2004.

BRASIL. Lei no 12.435, de 6 de julho de 2011. Lei do Sistema Único de Assistência Social.

BRASIL. Conselho Federal de Serviço Social. Lei no 8.662/93 de Regulamentação da Profissão. Código de Ética do/a assistente social. 10. ed. rev. e atual. - Brasília, 2012.

CONCEIÇAO, Alexandrina Luz. A geografia do Espaço da miséria. Revista eletrônica Scientia Plena, v. 1, n. 6, 2005.

GUERRA, Yolanda. Serviço Social brasileiro nos anos 2000: cenários, pelejas e desafios. In: Transformações societárias e Serviço Social: repercussões na cultura profissional. Organizadoras Ana Elizabete Mota e Angela Amaral. - Recife: Editora UFPE, 2014.

IAMAMOTO, Marilda Vilela. Serviço Social em tempo de Capital Fetiche. Capital Financeiro, trabalho e questão social. 8. dD. São Paulo: Cortez, 2014a.

IAMAMOTO, Marilda Vilela. Serviço Social na Contemporaneidade: trabalho e formação profissional. 25. ed. São Paulo: Cortez, 2014b.

MÉSZÁROS, Istvan. A montanha que devemos conquistar [recurso eletrônico]. 1. ed. São Paulo: Boitempo,2015.

MINAYO, Maria Cecília de Souza.; et al. Social: teoria, método e criatividade. 21. Ed. Petrópolis, RJ: Vozes, 1994.

MOTA, Ana Elizabete (org.). Desenvolvimento e construção de hegemonia: crescimento econômico e reprodução da desigualdade. São Paulo: Cortez, 2012.

NETTO, José Paulo. Introdução aos estudos de método de Marx. 1. ed. São Paulo: Expressão popular, 2011 ${ }^{\mathrm{a}}$.

NETTO, José Paulo. Capitalismo monopolista e serviço social. 8. ed. São Paulo: Cortez, $2011 b$.

SANTO, Maria Escolástica.; JIMENEZ, Suzana.; GONÇALVES, Ruth Maria de Paula. A produção e a gestão da pobreza: das relações entre capital, Estado e educação. As Políticas educacionais no contexto dos limites absolutos do Estado e do capital em crise. Orgs. NOMERIANO, Aline Soares et al. Maceió: coletivo Veredas, 2017. 


\section{Como referenciar este artigo}

SILVA, Maria Lucia.; SUOZA, Raimunda Áurea Dias. Trabalho e educação no contexto do Ensino Superior e formação do assistente social. Revista Ibero-Americana de Estudos em Educação, Araraquara, v. 14, n. 2, p. 559-572, abr./jun., 2019. E-ISSN: 1982-5587. DOI: 10.21723/riaee.v14i2.11694

Submetido em: 14/08/2018

Revisões requeridas: $15 / 11 / 2018$

Aprovado em: 10/01/2019 